\title{
A propósito de la economía libidinal capitalista*
}

\author{
Entrevista de Philipe Petit a Bernard Stiegler \\ Traducción del francés al español de Luis Alfonso Paláu-Castaño \\ Universidad Nacional de Colombia, Medellín, Colombia \\ lapalau@gmail.com
}

Philipe Petit: Para comenzar, ¿puede usted establecer un estado de los lugares de lo que llama la "crisis de la economía libidinal capitalista"? ¿Sería posible darle una visión de sus investigaciones actuales a un lector profano? El concepto de "economía libidinal capitalista" nos remite a la vez a Marx y a Freud. iPero no es un freudomarxista ordinario! Su recorrido intelectual tiene en cuenta autores alejados en el tiempo, como Aristóteles y Husserl, y obras contemporáneas como la del filósofo Gilbert Simondon (1924-1989) que, por lo demás, es la que más ha contado para usted...

Bernard Stiegler: Comencemos por la libido. Todas las civilizaciones son maneras de captar lo que Freud llamaba la energía libidinal para desviarla de los objetos sexuales con el fin de que se fije en objetos sociales, por los cuales ella se eleva. Una civilización es un proceso de sublimación por donde la potencia pulsional se transforma en energía social; sublimar quiere decir ante todo transformar.

Si en la actualidad puede parecer un viejo juego - por no decir reaccionario- hablar de "elevación", pienso que esta apariencia es una idea recibida, ella misma muy "reaccionaria", y que la afirmación de la necesidad de la elevación es, por el contrario, muy revolucionaria. Yo creo que se debe hacer una revolución en materia de economía libidinal. En esta perspectiva es necesario leer, por ejemplo, la obra que el joven filósofo finlandés, Pekka Himanen (2002), consagró a lo que él llama la ética hacker. La organización capitalista de la economía libidinal, que se ha formado a comienzos del siglo XX, arruinó esta economía y agotó la energía libidinal, lo que se traduce en un terrible proceso de desmotivación en las viejas sociedades industriales. La reconstitución de

Cómo citar: Petit, P. (2020). A propósito de la economía libidinal capitalista. Ciencias Sociales y Educación, 9(18), 237-259. https://doi.org/10.22395/csye.v9n18a11

Traducción realizada por Luis Alfonso Paláu-Castaño del texto de Petit (2008).

Recibido: 10 de abril de 2020.

Aprobado: 21 de agosto de 2020. 
esta energía, después de la pérdida que se ha comprobado en el curso de los últimos decenios, no va a ser automáticamente recuperable, y esto es lo que hay de más urgente en materia de economía general, para hablar como Georges Bataille (2007). Esto pasa por una reevaluación, en la economía a secas, de lo que Freud ha llamado la sublimación; se precisa refundar la vida económica, la inversión, la orientación de los desarrollos tecnológicos, la política industrial, etc., sobre la sublimación como fuerza social.

Sin embargo, si hay acá algo de arcaico en la cuestión de la elevación - que es menester entender ante todo como lo que se opone a la regresión, lo que es también la cuestión del superyó (no hay sublimación sin superyó ni a la inversa)—, y si puede haber aquí, más sutilmente, algo de metafísico (en el sentido en que, en la filosofía contemporánea, la metafísica es una ilusión del teórico fundada en un andamiaje conceptual robusto, coherente, pero también y sobre todo bien enraizado histórica como socialmente), tanto este arcaísmo como esta metafísica consisten en plantear el problema de la elevación y de la regresión en términos simplemente morales, y en fundamentar estos sobre simples oposiciones.

La más difundida de estas oposiciones en el occidente judío, cristiano y musulmán (el islam hace parte de Occidente; incluso si se ha diseminado a partir de lo que se llama el Oriente Medio, es una figura del monoteísmo, y es este el que constituye a Occidente con la herencia de los griegos, a los que nosotros los europeos precisamente hemos recibido por medio del islam - lo que tendemos a olvidar-), es la del bien y del mal. Ahora bien, sabemos en el presente que, cuando se opone absolutamente y con toda certidumbre el bien y el mal, es decir, apoyándose en un dogma - ya sea religioso o político, o los dos-, el bien se transforma ineluctablemente en mal: inquisición, gulag, terrorismo, bushismo. No hablo aquí de nazismo, puesto que este niega pura y simplemente la diferencia entre el bien y el mal.

Evidentemente no quiero decir que no hay diferencia entre el bien y el mal, y que el bien no es nada, como el mal. Muy por el contrario, lo que quiero decir es que esta diferencia es una composición y no una oposición. Ahora bien, la metafísica reposa, por regla general, en oposiciones y engendra siempre, al mismo tiempo, dogmas. Este dogmatismo puede ser religioso, fundado sobre una religión revelada, y conservador. O también puede ser revolucionario y "progresista", o aún liberal en el sentido de neoliberal. El dogma consiste, entonces, en perseguir toda ambición de una política pública y de una mutualización de las inversiones distintas a las fundamentadas en el provecho a corto plazo. Esto conduce ineludiblemente a que este neoliberalismo niegue de hecho toda diferencia entre el bien y el mal, y a imponer el reino de las pulsiones mientras habla en nombre del bien, dogmáticamente opuesto al mal. 
No quiero decir que no hay diferencia entre el bien y el mal. Por el contrario, quiero afirmar que lo que los distingue está inscrito en una cuestión más amplia, más rica y más compleja, que es la de la economía libidinal, es decir, de una economía de tendencias que no cesan de componer y, por ello, de economizarse, es decir, de contrariarse mutuamente y — diría yo con Simondon (2007)— de metaestabilizarse.

Ahora bien, esta economía es la que engendra la sublimación, es decir, objetos sociales (entre los cuales los objetos morales son una dimensión), pero de los que los objetos científicos, estéticos, espirituales, políticos o económicos, en el sentido corriente, son también casos — por lo demás ligados entre ellos por esta economía libidinal-, en la que se constituye lo que Foucault (1968) había llamado bien al comienzo la epistếmē, luego la arqueología del saber.

Toda sociedad supone un poder de sublimar, de organizar, de cultivar. Por definición, lo que debe ser cultivado es lo que no se produce de suyo; esto necesita de las instituciones, ya sean el chamán, el papado, la asamblea nacional o la ONU. Ahora bien, para que estas instituciones funcionen, es necesario que de una manera o de otra le den derecho a lo singular como fuente de todo porvenir y que, precisamente, ellas lo críen; que le pongan cuidado, lo incuben, lo nutran, lo modelen y, finalmente, lo celebren como ejemplo y jalón.

Una singularidad es una encarnación - y una ocurrencia social, histórica y geográfica- de lo que yo llamo lo consistente. La consistencia de lo consistente es lo que se tiene en otro plano distinto de la existencia; es lo que no puede ser objeto de una prueba, y mucho menos de un cálculo. Para hablar la lengua de los primeros filósofos griegos, es lo que no es descriptible apodícticamente. Una consistencia es un objeto de la sublimación. Un tal objeto es inexistente si es verdad que solo existe lo que está en el espacio y en el tiempo y lo que, en esta medida, es calculable.

El capitalismo está estructurado como una economía libidinal de la sublimación, pero de tal suerte que esta economía libidinal sometió todos los objetos del deseo al cálculo, es decir, a la desingularización, lo que se puede llamar con Max Weber y Marcel Gauchet un desencantamiento; y esto a un punto tal que esta economía libidinal capitalista se revela hoy autodestructora; se arruina por sí misma, lo que quiere decir también que destruye todas las consistencias y, con ellas, las existencias y los motivos de existir, pues una consistencia es ante todo un motivo. Una existencia humana se construye proyectándose hacia objetos de consistencia, es decir, de sublimación (los objetos del amor bajo todas sus formas: el amor de mi esposo, el amor por la geometría, el amor al arte, el amor por la patria, a Jesús, a la sabiduría, etc.), a falta de lo cual ya no se es una existencia, sino pura subsistencia. Vivir únicamente en función de las 
subsistencias, lo que se llama el consumismo, es tender a vivir y a pensar como cerdos, para retomar un título de Gilles Châtelet (2002). Traté de mostrarlo...

Philipe Petit: a través de Michel Foucault y de Max Weber, especialmente...

Bernard Stiegler: en efecto, fue releyéndolos que traté de reconstituir un pensamiento político ${ }^{1}$ que le dé derecho a la irreductibilidad de lo incalculable en una economía política fundada en y por una economía libidinal. ¿Qué es el capitalismo? Hay dos grandes pensadores del capitalismo: Max Weber y Karl Marx. Weber piensa el capitalismo del siglo XVIII, y en particular el que se forma entonces en los Estados Unidos. Marx se interesa en el del siglo XIX. Es solamente en el siglo XIX cuando aparece plenamente el capitalismo, con el maquinismo. Durante mucho tiempo, creí que el pensamiento de Max Weber era una idealización del capitalismo. Como Marx y los marxistas, yo creía que el capitalismo estaba esencialmente constituido por la aparición de la máquina, que era la industria.

Ahora bien, por razones que pasan por Foucault, pero ante todo por Platón, después por Sylvain Auroux, y por el trabajo que comencé hace veinte años a partir del comentario que Derrida hace de Platón, yo articulé la técnica y la memoria en una relación que creo indisoluble y primera, pero que ha sido siempre reprimida por la metafísica; y es lo que me ha conducido a la vez a revaluar el alcance de la obra de Weber y a reinscribir el devenir capitalista en una historia del espíritu sostenido por sus mnemotécnicas.

Traté de mostrar, con y contra Platón, que toda memoria es hipomnésica: la memoria, es decir, tanto la singularidad y la imaginación, supone siempre las técnicas de memorización. Mi memoria está en lo que yo hago. Incluso en este momento, usted mismo, usted tiene fichas sobre sus piernas. Y juntos, registramos esta conversación con una grabadora, que es un aparato mnemotecnológico. Mi agenda me ha recordado hoy que teníamos cita a las 3:30 de la tarde, etc. En toda sociedad, en toda relación humana, en todo gesto, desde el más trivial (como lavarse los dientes) hasta el más elaborado (como el que se puede ver en El misterio de Picasso) hay un objeto técnico o un medio técnico, y éste soporta siempre ya un elemento de memoria.

Ni la memoria social ni la memoria individual están simplemente en los cerebros de las gentes; están en los artefactos y en las relaciones que los cuerpos y los espíritus anudan entre esos artefactos, y a través de ellos entre ellos mismos. Es evidente que pasan muchas cosas en la memoria cerebral. Pero la plasticidad del cerebro es tal que sus acoplamientos con el entorno técnico

Sobre Foucault, véase en particular a Stiegler (2008a). 
son tan importantes como los procesos propiamente cerebrales, en particular, en lo que concierne a las hypomnémata, que son las mnemotécnicas propiamente hablando y que constituyen la condición de transmisión de los saberes por los cuales el individuo singular se levanta, por ejemplo, como alumno. Las hypomnémata son los objetos engendrados por la hypomnesis, es decir, por la artificialización y la exteriorización técnica de la memoria...

Philipe Petit: comentada por Foucault...

Bernard Stiegler: comentada por Foucault, pero primero por Platón en Fedro -el primero en introducir la cuestión del hypomnématon es Platón-, después por Derrida. Yo mismo trabajé hace muchos años en mostrar que Platón opone lo que él llama anamnesis a la hypomnesis. La anamnesis es para él el conocimiento verdadero que describe, así, el proceso de volverse a acordar: el recuerdo de las esencias que el alma — según la mitología platónica de la caída - ha olvidado al caer en el cuerpo y que la dialéctica permite reactivar; la dialéctica busca producir una tal reminiscencia. Esta manera de pensar el conocimiento desde la memoria proviene, por lo demás, de una larga tradición. Vernant mostró que los aedos se definen ellos mismos como prácticos de la memoria.

Es la estructura del conocimiento a priori que describe Platón, con su teoría de la dialéctica y la anamnesis, la que lo conduce a la teoría de las ideas. Las ideas son aquí formas a priori que Platón comienza a pensar veintitrés siglos antes de Kant (1978) que llamará a esto lo trascendental en su Crítica de la razón pura. Platón dice lo trascendental en el lenguaje aún casi mitológico de Grecia, planteando que conocer es volverse a acordar. Pero insiste sobre el hecho de que es recordar de una manera viva en la verdad del diálogo y en la vida del presente viviente, como decía también Husserl; en la vida del diálogo significa al contrario de lo que hacen los sofistas. En efecto, estos desarrollan técnicas de memorización. Estas mnemotécnicas tienen que ver con lo que Platón llama hypomnesis y que, según él, mortifican de alguna manera la memoria como la escritura, como la retórica; ellas la objetivan y la exteriorizan en los objetos hypomnésicos. Por ello, la debilitan y permiten, en particular, manipular las memorias vivientes y las almas de las que son las memorias, un poco como Patrick Le Lay afirmó producir, con la televisión, tiempo de cerebro disponible.

Es así como para Platón, la anamnesis no es del todo hypomnesis; no solo es necesario distinguirlas, sino que hay que oponerlas radicalmente. Condena, por consiguiente, el libro, mientras vive la paradoja de escribir libros. Ahora bien, la cuestión de la relación entre anamnesis e hypomnesis es más actual que nunca. Vivimos en la época de una extensión extraordinaria de las mnemotecnologías hipomnésicas en todos los dominios y en todos los aspectos de la vida, tanto 
a través del teléfono celular, las redes digitales, el GPS, como con los sistemas de ayuda a la decisión, los media en general, los chips RFID (identificación de radio frecuencia), y la biónica. Vivimos una verdadera revolución hipomnésica, y una gran parte de las tensiones que atraviesan en este momento al mundo está inducida por esta revolución.

Para aprehender correctamente estas cuestiones, es necesario generalizar las apuestas de la hypomnesis a toda forma de técnica. No se puede oponer la anamnesis y la hypomnesis, incluso si es necesario distinguirlas; hay hypomnesis sin anamnesis, pero - contrariamente a lo que sostiene Platón- no hay anamnesis sin hypomnesis. Lo que hace que el saber sea saber es que es transmisible de generación en generación. Esta transmisión se ha hecho posible por el hecho de que toda técnica juega espontáneamente un papel mnemotécnico: por ejemplo, el sílex tallado que conserva una parte de la memoria de los gestos de su talla. La hypomnesis - así generalizada a la técnica (que Leroi-Gourhan (1970) describe en este sentido como una tercera memoria que se añade a las memorias germinal y somática del viviente sexuado) — aparece constitutiva de la humanidad. Y esta es la aparición en la historia de los vivientes, de una forma de vida que se llama la existencia. Esta ex-sistencia es la que supone una ex-teriorización en una técnica que deviene espontáneamente hipomnésica. Pero es también lo que hace posible, al mismo tiempo, las manipulaciones que Platón denuncia en la sofística y de las que constatamos en la actualidad que constituyen una cuestión de escala industrial y mundial: las mnemotécnicas, habiéndose vuelto mnemotecnologías, de ahora en adelante están en el corazón del dinamismo económico.

A pesar de todo lo que permite creer el neurocentrismo ambiente, la memoria se conserva por medio de otros vectores distintos a los de la vía neurológica (somática) o de la vía genética (germinal). Todos los seres vivientes sexuados están constituidos por dos memorias: la memoria de la especie (genética) y la memoria nerviosa (individual). Ahora bien, los seres humanos, en tanto que seres vivos que ex-sisten, tienen una tercera memoria, y es ella la que constituye la posibilidad de lo que se llama la cultura y el espíritu. Aquí regreso a su pregunta inicial: la cuestión del inconsciente, el hecho de que la sexuación, el instinto sexual, pueda transformarse en pulsiones ligadas por lo que se llama la libido, esto es, una energía - dice Freud- libidinal que es producida por una economía libidinal. Este hecho supone que esta energía sea capaz de desprenderse del objeto sexual, y esta posibilidad de desapego de los objetos sexuales está esencialmente ligada a esta tercera memoria en tanto que constituida - dice Leroi-Gourhan- por la amovilidad de los objetos técnicos. El ser humano, en tanto que es técnico, se dota de órganos amovibles, a diferencia de los animales cuyos órganos están dados por su naturaleza. Esta amovilidad de los objetos 
técnicos es la que induce también una amovilidad de los objetos del deseo. Y esto hace posible lo que Freud describe a la vez como una sublimación y como la capacidad de la libido a fijarse en cualquier objeto o perversión. Para decirlo de otra manera, pienso que hay "medios de producción" de esta economía libidinal y que esos "medios" son técnicos, es decir, también farmacológicos: esencialmente ambivalentes, a la vez remedio y veneno, como lo dice Platón de la hypomnesis ${ }^{2}$. Pues esta tercera memoria es la que abre la posibilidad misma del inconsciente; es ella la que permite los procesos tanto de transmisión de traumatismos entre las generaciones como de represión de esos traumatismos.

Philipe Petit. ¿Puede usted retomar estas tres memorias y decirnos por qué la tercera memoria es fundadora de la civilización?

Bernard Stiegler. La primera es la memoria específica que August Weismann llamaba el germen y que se llama hoy el genoma; la segunda es la memoria nerviosa, neurológica, que Weismann llamaba el soma: es la que se forma por la organización de las sinapsis, sobre la cual aprendemos tantas cosas por medio de la imagenología cerebral; y la tercera es la memoria que yo llamo epifilogenética (Stiegler, 2002), que hace que tal objeto fabricado, manufacturado o hecho a máquina, guarde la memoria de las condiciones de su producción, de la que él es una exteriorización; es una traza de memoria y se vuelve por ello espontáneamente hypomnésico.

En la memoria epifilogenética — que está constituida por todos los artefactos de cualquier naturaleza-, es necesario distinguir las técnicas que son específicamente concebidas para permitir la producción y la transmisión de la memoria: estas son las hypomnémata en sentido estricto. Un hypomnématon es un soporte de este proceso de exteriorización de la memoria que es la hypomnesis, y que permite ampliar artificialmente las capacidades mnésicas de la memoria nerviosa. Pero esta exteriorización es también lo que hace posibles operaciones mentales nuevas, por ejemplo, de digitalización o de tipos de razonamientos. Husserl establece así que no puede haber razonamiento geométrico sin la escritura alfabética. Las hypomnémata son también los soportes de las técnicas de sí de las que habla Foucault, y por las cuales un individuo psíquico puede intensificar su individuación. De forma más general, las hypomnémata son los soportes del otium, es decir, del desarrollo de la libertad de espíritu. Después de Platón - y durante siglos-, los estoicos, los epicúreos, los cristianos primitivos, luego la clerecía en general y, en fin: todos los que se han llamado los "sabios" (clerc), comprendidos los laicos, se vuelven prácticos de las hypomnémata.

Desarrollo sobre la base de estas consideraciones el proyecto de una farmacología general en Prendre soin: de la jeunesse et des générations (Stiegler, 2008a). 
Es aquí donde es muy interesante acercarse a lo que Foucault dice de las hypomnémata en sus últimos textos en los que analiza la génesis espiritual del capitalismo que hacía Weber en 1905. Las hypomnémata, por lo demás, son también las condiciones de lo que Las palabras y las cosas y La arqueología del saber describían como técnicas de archivado, clasificación, cuadros, dispositivos de escritura, etc. (Stiegler, 2008a). Pero estas técnicas, que pueden intensificar los procesos de individuación y desarrollar la libertad de espíritu, son también las que permiten su control y su destrucción.

A partir de la teoría freudiana, sabemos que la apuesta de los análisis de Max Weber — que plantea que la nueva espiritualidad salida de la Reforma es la fuente histórica del desarrollo del capitalismo- es la libido tal como ella se sublima en un asunto de creencia. Pero aquí el punto importante es que esta nueva forma de la sublimación se produce por el desarrollo del libro impreso, que está en el origen de la nueva espiritualidad y que es también —como hypomnématon- el soporte de los libros de cuentas. En este sentido, permiten la aparición de la contabilidad, del cálculo y, por tanto, de lo que va a transformar la creencia irracional en confianza racionalmente calculada.

Sostengo que el problema del capitalismo actual —que está al borde de la autodestrucción- es esencialmente el de una refuncionalización de los mecanismos de creencia. Y yo creo que tanto ese problema como su solución histórica, pasa por tener en cuenta el papel de las formas contemporáneas de hypomnémata, las cuales pueden contribuir tanto al desarrollo de una nueva forma de sublimación, a un control creciente de los individuos, como a la prosecución de su desindividuación.

Weber mostró que el espíritu del capitalismo conducía inevitablemente a un proceso de racionalización salido de una creencia religiosa, pero que no podía sino liquidar esta creencia por el cálculo. Al mismo tiempo, subrayaba que el capitalismo, como sistema de crédito, no podía, sin embargo, prescindir de un espíritu que organizara la motivación sin la cual ya no hay ningún dinamismo social. Una tal motivación es evidentemente del orden de una creencia en los motivos que la animan (que están ligados - lo he indicado hace un momento- a lo que llamo las consistencias). Ahora bien, lo que Marcuse ha descrito como resublimación ha conducido en nuestros días a la liquidación de todas las motivaciones (y de todas las consistencias). De ello resulta una pérdida de confianza - y no solamente de creencia- que es una catástrofe para todas las formas de inversión, es decir, para la economía capitalista en su principio mismo (que reposa precisamente sobre el desarrollo sistemático de todas las posibilidades de inversión). Notemos, de paso, que la inversión (investissement) es uno de los grandes conceptos de Freud. 
Yo he llegado a este terreno a través de cuestiones ligadas a la estética; entonces me interrogaba sobre la inversión estética del capital, sobre la dimensión cada vez más estética del capital; en efecto, el capital ha devenido ante todo una estética. Por las marcas, por la hechura de los modos de vida. El capitalismo es lo que fabrica los modos de vida de los individuos...

Philipe Petit: ¿Jeremy Rifkin fue determinante en este trecho?

Bernard Stiegler: Quizás no tanto como determinante, pues fue por medio del análisis organológico que yo empecé en el Instituto de Investigación y Coordinación de Música/Acústica (Ircam por sus siglas en francés) y por necesidades profesionales de comprensión del devenir de la música, que me metí por esa vía a través del concepto de lo que he llamado organología general. Para pensarla organicé un coloquio en Cerisy con el Ircam y el Centro Nacional para la Investigación Científica (CNRS por sus siglas en francés) en colaboración con Georges Collins, y publiqué con Nicolas Donin Revoluciones industriales de la música (Donin y Stiegler, 2004). Pero, ciertamente, Rifkin ha sido fundamental en esta reflexión por todos los datos que reunió sobre lo que él llama el "capitalismo cultural" incluso si yo encuentro que su aparato teórico es muy débil. Su fuerza es también su debilidad: va extremadamente rápido, pero simplifica a ultranza. Pero de todos modos muestra de una manera perfectamente clara y muy bien informada cómo y por qué el capitalismo se volvió cultural. Pero esto significa para mí que el capitalismo, más que nunca, debe ser descrito como una máquina libidinal.

Philipe Petit: Es una vieja cuestión, está presente de una manera arqueológica o críptica en Marx en ese famoso discurso sobre el fetichismo de las mercancías.

Bernard Stiegler: Ciertamente. Y, sin embargo, pienso que el capitalismo del siglo XX se vuelve esencialmente una economía libidinal en un sentido que va mucho más allá de este análisis célebre del fetichismo de la mercancía. El capitalista del siglo XX — cuyo ideal tipo es Henry Ford - toma conciencia de que la cuestión fundamental ya no es la producción, sino el consumo; el primer objetivo se vuelve la captación de la libido del consumidor.

Este proceso comienza en los inicios del siglo XX; incluso se podría decir que se anuncia mucho antes, con los "grandes almacenes", con todo lo que va a consistir en escenificar la mercancía o en intensificar su fetichismo. Pero esto solo comienza a ser verdaderamente teorizado después de Freud, y por un sobrino de Freud, Edward Bernays (2007). Desde entonces, este sistema, ante todo 
consumista, que se desarrolla mundialmente, conduce a lo que Rifkin describe como capitalismo cultural, donde los mass-media transforman en totalidad los modos de vida hasta el punto de llegar en el día de hoy a destruir las estructuras familiares, las escuelas y las instituciones públicas en general, para no hablar de la propia democracia ${ }^{3}$.

En resumen, la fabricación del material audiovisual, los satélites de comunicación y ahora lo digital, todas las nuevas formas de la hypomnesis y de las hypomnémata, forman un aparato de captación de la libido que se ha vuelto una infraestructura mundial desde la formación, en 1992, de la red Internet fundada sobre la norma TCP-IP.

Desde 1944, Adorno había comprendido este vínculo entre la libido y el capital. Pero el problema con los filósofos de la Escuela de Fráncfort, Adorno, Marcuse y Habermas especialmente, es que siguen pensando la técnica con los clichés heredados de la metafísica, bien sea porque están demasiado influidos por Heidegger (como Marcuse) o porque tienen una visión marxista demasiado estrecha de la técnica, como Adorno y Habermas. No ven la necesidad de criticar la concepción marxista de la industria tanto como del capital. No ven que Marx no es suficiente para pensar el consumo. Es acá donde yo encuentro un interés renovado por Max Weber.

Philipe Petit: ¿A propósito de los mecanismos de la creencia?

Bernard Stiegler: De la creencia, pero también del vínculo entre espiritualidad, técnicas contables y racionalización. Max Weber aparece luminoso si nos ponemos de acuerdo en decir que el capitalismo es ante todo un dispositivo de captar crédito, antes de ser una inversión en la máquina. Y el protocapitalista descrito por Weber es el que sabe poner en relación productores y consumidores, y controlar esta relación: como relación de confianza, y sobre la base de una creencia que da también una ética, la famosa "ética del trabajo".

En el período precapitalista, en el Occidente monoteísta, el crédito es religioso; todos los poderes están fundamentados sobre un crédito religioso que plantea, en principio, que hay una esfera trascendente que no puede ser objeto de cálculos. Esta esfera de la creencia, precisamente porque no puede ser objeto de cálculos, es legitimadora del poder. Permite, por ejemplo, un poder de derecho divino y funda el poder de los sabios en general, que por naturaleza escapa a la esfera de la producción. Ahora bien, la esfera de la producción es la esfera del cálculo, es la esfera de lo que los romanos llamaban el nec-otium. El negotium es

Esta hipótesis está explorada en La télécratie contre la démocratie. Lettre ouverte aux représentants politiques (Stiegler, 2006). 
lo que es del orden del cálculo. Es lo contrario del skholè y del otium, donde se está libre de las obligaciones de la vida cotidiana consagradas a la satisfacción de las necesidades por medio de la producción de las subsistencias.

Hasta fines del siglo XVIII, la sociedad está constituida por una oposición entre la esfera de las necesidades, con la que tienen que ver los esclavos, los artesanos, los plebeyos; y la esfera del otium, es decir, las formas más sublimadas del deseo y como acceso a lo bello, a lo verdadero y a lo justo. Estos clérigos están orgánicamente ligados con los nobles, que son combatientes ante todo y, por ello, seres libres. Sin embargo, la concepción de esta libertad va a evolucionar con la laicización de los sabios que, con la república de las letras, van cada vez más a venir con frecuencia de la esfera plebeya. Esto es lo que va a conducir a la Aufklärung.

Durante mucho tiempo los sabios son, sin embargo, religiosos. Han hecho el voto de castidad y, excluyéndose de la reproducción de la especie, se alejan de la subsistencia individual igualmente en ese mismo plano. Esta retención es también una manera de radicalizar el proceso de sublimación por donde, al retirarse de la vida ordinaria, cultivan un saber de lo extraordinario y acceden a la esfera de lo incalculable, a la esfera de lo que no existe (al menos según las vías de lo que, al existir, es calculable), sino que consiste. Lo que existe sobre el plano ordinario se calcula, es objeto de transacciones, de mercados, etc.

Durante mucho tiempo, hasta el siglo XIX, las sociedades reposaron sobre esta gran repartición. Ya sea que vayáis al Tíbet, con los monjes budistas; a Siberia con los chamanes; a Grecia o a Roma antiguas con los filósofos que cultivaban la epimeleia (el cuidado de sí) por medio de la práctica de la skholè; o también a las tierras cristianas o islámicas con sus oficiantes; todas esas sociedades reposan sobre esta gran partición de las actividades humanas entre vidas sometidas a las subsistencias y las consagradas a las consistencias. Estos dos modos de vida, distintos pero inseparables, forman lo que Bataille llamaba una economía general. Su repartición se opera según modelos extremadamente variados: según las formas de prácticas intelectuales y espirituales de religiones, creencias y vida espiritual y, ante todo, según el tamaño de las sociedades. Una sociedad de cincuenta personas en la Amazonía no está organizada de la misma manera que el imperio egipcio o que el imperio germano cristiano. Pero la separación entre las esferas de lo que yo llamo las subsistencias y las consistencias, sea entre categorías de poblaciones, sea entre momentos de la vida, es común a todas esas organizaciones; es estructural, constituye la solidez de lo social y forma los lazos entre los miembros de la sociedad. Es esto lo que comprende Weber en el momento en que muestra cómo el capitalismo destruye esta repartición. 
Retomemos brevemente su análisis. El luteranismo, dice él, condena el monaquismo; condena tanto los fastos de la Iglesia como la separación entre los monasterios y la sociedad, en la que ve un olvido del sentido de la vida de Jesús. La Iglesia se ha vuelto un sistema de captación del impuesto y, por tanto, de coerción; se ha vuelto exactamente lo contrario de lo que debía ser, y esta transformación es una corrupción del dispositivo de sublimación en el que consiste. La denuncia de esta corrupción se produce en el contexto del desarrollo de la imprenta, que permite a Lutero preconizar una nueva práctica de la lectura y una relación de todos los fieles con los hypomnémata. Cada uno debe poder leer la Biblia en lengua vernácula y, por tanto, no aprender a leer una lengua muerta, sino en la lengua viva del negotium; es necesario creer en el mundo del negotium, dice la Reforma. Creer verdaderamente es pues, según Lutero, superar la oposición entre el negotium y el otium. Es menester que la vida de todos los días sea la aureola de Dios; él protesta contra la santurronería y salva a la vez el comercio y la oración, el enriquecimiento y la salvación. Tal es la revolución espiritual que está en el origen de la formación de la ética protestante.

Philipe Petit: ¿Es una refundición del medio técnico?

Bernard Stiegler: Es evidente que este devenir se inscribe en un grandísimo trastorno técnico, en el que la mnemotécnica de la imprenta sobredetermina todo el resto; y concreta lo que Sylvain Auroux (1994) llamó la segunda revolución tecnológica de la gramatización. La circulación de estos nuevos tipos de hypomnémata que son los libros induce una vida del espíritu completamente nueva, pero que se acompaña — como lo subraya Weber- de una evolución de la contabilidad; los hypomnémata son también los libros de cuentas. En este contexto, se puede decir que, en una cierta medida, Lutero y sobre todo Calvino van a poner lo religioso al servicio de lo económico, mientras que estaba hasta entonces al servicio de lo político, así como de lo teológico-político.

Es extraño que Foucault no hubiese revisitado con sus propias hipótesis lo que así describe Weber. Pues Foucault (1998) muestra que en la misma época se ponen en funcionamiento tecnologías de poder, que forman lo que él llama un biopoder, precisamente a través de un "aparato de escritura" y un "poder de escritura" (p. 194), mientras que al final de su vida se asoma a los hypomnémata como tecnologías del espíritu. Pero, en lo que yo conozco, nunca relacionó las dos. Ahora bien, esto es, en un cierto sentido, lo que Weber no solamente hace posible, sino necesario. Es particularmente legible en su lectura de los "sermones" de Benjamin Franklin. 
Philipe Petit: ¿Usted retoma pues por su cuenta la tesis de Weber sobre Benjamin Franklin?

Bernard Stiegler: Completamente. En el momento en que Benjamin Franklin aparece, en la segunda mitad del siglo XVIII, el capitalismo en el sentido definido por Weber se desarrollaba ya desde hacía algunos decenios, y en un contexto en el que Franklin podía sostener que la creencia debe estar fundamentada en el cálculo. Ser piadoso, es decir, ser calvinista, es ser capaz de crear la armonía perfecta entre lo que creo y lo que cuento (compte). Y es lo que lo lleva a la formulación de ese enunciado que se volvió célebre y definitorio del estado de espíritu norteamericano: "El tiempo es oro".

Georges Bataille (1949) escribió frases terribles sobre Franklin en una nota de La parte maldita, verosímilmente inspirada en una lectura de Weber. Franklin dice que si, por ejemplo, pierdo tiempo quedándome en mi cama en lugar de ganar dos dólares con los cuales hubiera podido comprar un cerdillo que hubiera podido tener otros... a fin de cuentas, mi pereza ha costado mil marranas —a mí, pero también a la creación-. He cometido un pecado del que Franklin calcula el precio. Puede parecer grotesco y, sin embargo, traduce bastante precisamente el espíritu del capitalismo tal como lo describe Weber y tal como lo execra Bataille. Es la transformación del crédito salido de la fe en un crédito calculable que tiene que ver cada vez menos con una tal fe y cada vez más con una confianza matematizable, en particular, a través de los formalismos de las probabilidades. El dólar es la divisa que deberá encarnar la edad de la confianza en la modernización industrial, tanto como el crédito que puede calcularse en el mercado de cambios. Aquí, lo fiduciario se apoya en lo confesional al mismo tiempo que lo reduce a nada.

Si se encuentra sobre el dólar la divisa In God we trust y no In God we believe, es porque el espíritu del capitalismo es lo que sustituye la creencia por la confianza, lo que hace calculable al objeto de la creencia ${ }^{4}$. Ahora bien, es una paradoja: un objeto de creencia no puede ser calculable. Solo se puede creer en aquello en lo que se puede dudar precisamente porque es incalculable. Este punto está ligado al hecho de que conocer no es creer. Por ejemplo, no se puede decir que usted cree en el teorema de Pitágoras. No se puede creer en Einstein. $O$ bien se prueba a Einstein o se lo refuta.

Ahora bien, tanto en el espíritu del capitalismo, salido de la ética protestante, como en una parte al menos del pensamiento de la Ilustración, existe la tentación a agotar el mundo de la creencia en el del saber y a reducir la cuestión de la razón a la de la ratio y a la calculabilidad; el espíritu del capitalismo y el

Sobre estos temas, véase Stiegler (2004), especialmente los capítulos 13 y 14: "Capitalismo y creencia" y "Tiempo y cálculo en la época capitalista". Nota del traductor. 
Siglo de las Luces -y Franklin se presentaría como un Aufklärer americanoson consecuencias de la mathesis universalis concebida como ratio. La manera de ver que de ello resulta - y que fue durante tanto tiempo la mía-, donde se trata de absorber, de resolver y, finalmente, de disolver el mundo de la creencia en el del saber, es una absurdidad.

Ninguna sociedad funciona si es incapaz de proyectar en un horizonte de creencia algo que no puede ser objeto de un saber, y que sin embargo es constitutivo de todas las formas de saber. Todas las formas de saber (de la mundología al saber teórico que es el conocimiento, pasando por las habilidades) irradian a partir de un aparato de proyección de creencias, creencias que se distinguen de los objetos de saber (porque saber no es precisamente creer), pero sin las cuales los objetos de saber que rebasan esas creencias no podrían formarse. Pues los objetos de creencia son objetos de deseo. Y los objetos de saber son ellos mismos sublimaciones de esos objetos de deseo.

El objeto del deseo es, por naturaleza, un objeto infinito; en caso contrario sería un objeto de necesidad. El objeto del deseo es un objeto de la existencia, y el de la necesidad es un objeto de la subsistencia. El objeto del deseo es incalculable en que, como objeto de la existencia, no puede constituirse sino proyectándose en un plano de consistencia donde se vuelve completamente singular, y por ello deseable, pero también incomparable y, por tanto, incalculable. El objeto de saber es calculable. Pero, en tanto que objeto del saber, él proyecta sobre y en su calculabilidad el carácter infinito del saber mismo. Si los objetos de saber son finitos y calculables, el saber mismo es infinito y no es totalizable. En esto, el saber es lo que anuda el cálculo y lo infinito; a esto se lo llama la sublimación. Por esto, los objetos del saber solo toman su sentido cuando se proyectan en el plano de consistencias donde se transforman en objetos que no existen. Los objetos de saber son calculables, pero sobre la base de los incalculables y de los indemostrables. Por ello, son objetos ideales cuya calculabilidad no puede ser reducida a la que está en vigor en las subsistencias. El punto geométrico no existe, no está ni en el espacio ni en el tiempo.

Este mecanismo de proyección por donde se constituyen las consistencias que fundan los saberes, es más generalmente el horizonte de sublimación bajo todas sus formas. La sublimación constituye las capas de la existencia que van de las reglas de cortesía hasta Einstein, pasando por el amor, la filosofía, el deporte, el arte, la religión y mil otras cosas que son los objetos de las pasiones sublimadoras y sublimadas. Tal es la vida del deseo: el deseo es lo que es capaz de producir objetos de saber (vivir, hacer, teorizar), sublimando la sexualidad que está en la base de la subsistencia, como objetos de conocimiento o de adoración que conllevan siempre un misterio del saber, el de la esencia infinita de 
todo saber. Si estos objetos no comportaran en ellos esa dimensión que es del orden del misterio, que traspasa la administración de una prueba por el cálculo, no serían objetos de saber, es decir, de sublimación; no serían objetos de lo que se llama el espíritu donde se reúnen las cosas elevadas.

Philipe Petit: ¿Por qué hablar del espíritu y de las cosas elevadas?

Bernard Stiegler: Lo que hace que un cuarteto de Beethoven sea un objeto del espíritu, por ejemplo, se lo sabe de entrada (y aquí sería necesario distinguir saber y conocer, distinguir el conocimiento en el saber, y como una forma muy específica del saber que está generalizado, pero que durante mucho tiempo fue excepcional; el saber no es necesariamente un saber de lo que sé que yo sé; por ejemplo, un niño que sabe hablar una lengua que no sabe leer, es decir, sabe su lengua sin saber lo que sabe, sin conocer su lengua). Este cuarteto de Beethoven engendró múltiples interpretaciones nuevas. Una infinidad de las interpretaciones en derecho, que es, de hecho, un indefinido y un indeterminado, está inscrita en la estructura de ese cuarteto. A esto es a lo que llamamos el espíritu, y que es claramente una especie de misterio, pues no se podrá nunca calcular una interpretación perfecta de ese cuarteto, una última interpretación que sería, en esta medida, una interpretación finita y el final de toda interpretación de ese cuarteto. De la misma manera, por ejemplo, Einstein delimitó la teoría de Newton, pero él nunca dijo que él constituía finalmente la mejor interpretación de Newton; si lo hubiera hecho habría significado que con Einstein la física estaba acabada. Einstein nunca dijo que Einstein no sería él mismo reinterpretable por otra teoría. Y nunca un científico ha creído semejante cosa, y nunca ninguno lo creerá. Esta es una consecuencia de lo que Kant (1978) escribe en la Critica de la razón pura:

No es raro que, comparando los pensamientos expresados por un autor acerca de su tema, tanto en el lenguaje ordinario como en los libros, lleguemos a entenderle mejor de lo que él se ha entendido a sí mismo. En efecto, al no precisar suficientemente su concepto, ese autor hablaba, o pensaba incluso, de forma contraria a su propio objetivo. (p. 310)

Es esto lo que hace posible la inscripción de Newton en Einstein, y de Einstein en un porvenir abierto de la física. Ahora bien, esta infinitud del espíritu es una estructura de la economía libidinal. La infinitud del objeto del espíritu es por completo homogénea con el hecho de que el objeto de un amor es un objeto infinito. Solo se puede amar infinitamente; no se puede amar a medias o al diez por ciento. Ahora bien, esto significa también que los saberes - cuyos objetos son siempre construcciones de la sublimación- son expresiones de la singularidad irreducible de sus objetos. El sabor de estos objetos —en saber 
está sapere, y por esto un saber es sápido; él es saber acceder a esos sabores que son sus objetos- tiene que ver con ese carácter irreductiblemente singular.

La gran cuestión de las sociedades es siempre, en última instancia, saber cómo se produce lo singular, es decir, también sabores, y esto nos remite hacia la creencia. Pues no podemos sino creer en lo singular, en tanto que él es el objeto de un deseo en el cual aparece su singularidad. Se puede formalizar esta singularidad por medio de cálculos, pero no se puede reducir la singularidad del objeto a esta calculabilidad ni a esta formalización pues, si tal fuese el caso, el saber sería finito. Ahora bien, un saber es en derecho tan infinito como un cuarteto de Beethoven es irreducible a una interpretación perfecta. El saber es siempre el saber de lo que hace falta, y que eso que hace falta y es defectuoso, es sabroso. Dicho de otro modo, se puede saber de aquello de lo que solo sabemos que nos contentamos con creer, pero no podemos saber sin creer en la singularidad de su objeto de saber y, por tanto, en la infinitud de ese saber mismo.

Todos los objetos de sublimación suponen una creencia capaz de proyectar su singularidad. Cuando nos enamoramos de una persona creemos en su singularidad, es decir, en su incomparabilidad (y cuando ya no la queremos, ya no creemos más en eso). Completamente, como en el museo, tenemos que creer en las obras de arte. Ahora bien, por una parte, esta creencia - que es la que fundamenta la unidad de lo social- es frágil, y debe ser mantenida como máquina de sublimar; y, por otra parte, esta máquina ha sido destruida por la evolución reciente del capitalismo. Es lo que Herbert Marcuse llamó el proceso de desublimación, y también aquello sobre cuyas consecuencias medita Marcel Gauchet.

Philipe Petit: Vivimos en una época de dudas terribles sobre las obras artísticas, los descubrimientos científicos, el sentimiento religioso... Estas dudas se expresan a través de un reciclado cultural que se impone al espíritu a tal punto que la fuerza misma de ese reciclado se nos escapa. Los cultos y la disciplina parecen diseminarse en una terrible indistinción...

Bernard Stiegler: Usted podría también hablar aquí de las obras políticas y económicas. Y es así porque la creencia debe ser objeto de un cuidado, de un culto religioso o laico, de una cultura y de un entrenamiento en el sentido en que los griegos hablaban de gymnasia, cuyo nombre han conservado los establecimientos de enseñanza germánica. No existe ninguna religión sin ritual porque la creencia religiosa debe cuidarse, como toda forma de creencia. Pero esto es verdad de todas las formas del otium, y todos los saberes son formas del otium. Personalmente, leo y escribo todas las mañanas, y practico eso como un culto y como una lucha contra mí mismo, contra lo que está en mí como mi minoría de edad, causada por lo que Kant (1964) llama mi pereza y mi cobardía. Ya no nos 
atrevemos a llamar a esto la cultura, de la que Moses Mendelssohn nos enseña que ella pertenece (como kultur) a la bildung, que es una formación del espíritu y un culto en este sentido. Ya no nos atrevemos a hablar de ello porque la palabra cultura ha sido a tal punto rebajada a lo consumible y a lo comportamental, que se ha constituido en industria cultural (lo que Michel Deguy llama precisamente "lo cultural"); y hemos terminado por olvidar esta necesidad.

Philipe Petit: Usted ha dicho que la creencia hace parte del crédito del capitalismo. ¿En qué sentido? ¿Podría Usted precisar su concepción de la creencia?

Bernard Stiegler: La creencia puede tomar formas muy variables. La creencia religiosa está próxima de la creencia política. La creencia artística es otra forma. La creencia amorosa igualmente. Existe todo tipo de formas de creencia. La práctica científica sin creencia no existe, incluso si —como Aristóteles-se la llama entonces lo verosímil, que es el carácter de los axiomas improbables (que no pueden ser probados) que están en el fundamento de todo saber apodíctico, es decir, demostrativo. Dicho esto, la creencia ha sido - sobre todo después del siglo XVIII- el objeto de una formalización, de una matematización y de una algoritmización sistemáticas con el fin de transformarla en calculabilidad, es decir, también en confianza y en probabilidad. Ahora bien, ese devenir es ante todo una evolución económica; el capitalismo se forma ante todo como un sistema de calculabilidad. Después se desarrolló a través del maquinismo que aportó a esta calculabilidad increíbles posibilidades de extensión y de acción, tanto en el dominio de los instrumentos del cálculo científico como para el control de los comportamientos de producción y los comportamientos de consumo. Así, proletarizó, al mismo tiempo, a los productores y a los consumidores con el fin de constituir enormes mercados.

Estos dispositivos son, en el presente, máquinas de calcular planetarias reguladas con miras a producir creencias, es decir, crédito en el sentido bancario, puesto que finalmente todo esto se ha vuelto el crédito bancario. El problema es que esto solo puede funcionar calculando los objetos de creencia que se vuelven, así, ante todo objetos de confianza, después objetos de descrédito; el cálculo es lo que destruye ineluctablemente la creencia. Por tanto, la confianza no puede suceder durablemente; es lo que vivimos en la actualidad, en particular con llevar al extremo esta situación por parte de los hedge funds, y esto significa que esta máquina está chirriando completamente.

Philipe Petit: ¿Y no en la dirección indicada por Marx?

Bernard Stiegler: Es necesario, en efecto, reinterpretar lo que dice Marx con respecto al maquinismo, y es necesario para ello tomar consciencia del hecho 
de que el maquinismo prosigue el proceso de exteriorización del que proceden las hypomnémata, en un sentido en que el solo Marx no permite pensar. ¿Qué es el maquinismo con respecto a la imprenta? De hecho, es la prosecución de la imprenta. ¿Pues, qué es la imprenta? Es ante todo la posibilidad de reproducir lo que la máquina-herramienta desarrollará a nivel de los objetos. Es enseguida la posibilidad de desarrollar la lectura de masa. Sylvain Auroux (1994) llama a esto el proceso de gramatización.

Philipe Petit: ¿Comenzó en los inicios de la escritura entre los egipcios y los mesopotámicos?

Bernard Stiegler: Los procedimientos de escritura que, en efecto, se forman ante todo como sistemas de numeración de los grandes imperios, son dispositivos que permiten la repartición del continuo en unidades discretas (discretización). En el origen de Occidente, hay constitución del alfabeto que resulta de la gramatización, cuyo proceso se arma como un resorte con los sistemas de numeración que son también escrituras hieráticas. Y el alfabeto que funda la ciudad y el derecho público, es decir, profano, está en la base de la Biblia, de las tres religiones del libro y, por tanto, de la forma occidental de la creencia. El alfabeto religa todas las creencias de las religiones de Occidente. Pero el alfabeto permite igualmente la discretización del flujo continuo en la palabra. En las sociedades sin letra ni numeración con notación, la palabra aparece como la continuidad de un mana. En las sociedades arcaicas, la palabra como potencia tiene que ver con lo que Lévi-Strauss describe como ese mana, retomando una palabra maorí. El mana es una fuerza, una energía que "se apodera" de los objetos, que llamaríamos "sobrenatural", y que es el continuo, lo indeterminado, lo no discretizado. Cuando un hopi o un maorí hablan, "ello" (ça) habla en ellos; es la fuerza que los posee que pasa por ellos, y esta fuerza es una; es un continuo y es un "espíritu". Ahora bien, a partir de lo que Auroux llama la primera revolución tecnológica de la gramatización (que es la aparición del alfabeto), el flujo continuo de la palabra es discretizado, y el habla se vuelve lo que Saussure llamaba la lengua, por donde el "espíritu" deviene también logos.

La segunda revolución tecnológica de la gramatización - de la que la imprenta es la concretización y la socialización masiva— va a generalizar la discretización del continuo lengüeril. Y después vendrá la revolución del maquinismo, que es engendrada ella misma por esta revolución de la imprenta. Pues esta va a hacer que las ideas circulen y, con ellas, la técnica y la ciencia van a tomar un nuevo sitio en la sociedad y anudar una nueva relación. Además, es extraordinario que, en el momento mismo en que la imprenta se socializa, es descubierta América; y esto no es algo anodino: la imprenta está en el horizonte de la audacia de Colón. 
En el siglo XIX se constituye un nuevo estadio de la gramatización que ya no es simplemente el del flujo verbal, sino el de ese flujo continuo que también es el gesto. La máquina es la prosecución de la formalización discretizada del continuo en un dominio que ya no es simplemente el del logos. Durante siglos, solamente la palabra - y luego la música - fueron discretizadas por sistemas formales. Ahora bien, hacia fines del siglo XVIII, James Watt cambia la mano (del juego) cuando, encontrándose con Matthew Boulton (en 1767), crea las condiciones de aparición de la máquina-herramienta, de la que Adam Smith esbozará los principales caracteres en 1776 en La riqueza de las naciones. Boulton es típicamente un capitalista en el sentido en que Weber lo ha descrito: es el que comprende la necesidad de innovar. Pero, en el siglo XVIII, el protocapitalista innova ante todo en los modos de distribución y en la organización de la producción; relaciona a productores y compradores, amplía los mercados, pero con ello crea necesidades nuevas. Es así como comienza el capitalismo para Weber.

\section{Philipe Petit: ¿Y para Marx?}

Bernard Stiegler: Verdaderamente solo comienza con Watt y Boulton, es decir, con el maquinismo y lo que El capital llama "la gran industria". Ahora bien, las máquinas industriales permiten formalizar, discretizar y reproducir los gestos de fabricación; duplicar las habilidades del obrero y hacerlas pasar a la máquina. El maquinismo industrial reproduce los gestos del trabajo, así como la escritura permite reproducir las palabras y la imprenta permite reproducir los ejemplares. Esto también permite racionalizar esos gestos de la misma manera en que la escritura permite racionalizar una manera de escribir y, por tanto, de hablar y, por tanto, de pensar, en lo que va a volverse un medio lengüeril homogéneo. Es lo que pasó con el griego ático y con el francés salido de la ordenanza de Villers-Cotterêts.

Philipe Petit: La gramatización implica, pues, una mundialización, para no decir una desterritorialización, que comenzó con la escritura y que se prosiguió con la máquina.

Bernard Stiegler: Sí. Y con el maquinismo ya no se trata simplemente de la desterritorialización de los comportamientos verbales y de los corporales, sino de una deslocalización tal que, a partir del momento en que puedo reemplazar los obreros por las máquinas, puedo exportar las habilidades a cualquier lugar. Ya no se trata, por lo mismo, de habilidad, sino de un sistema-experto encapsulado en una máquina programable; puedo hacer fabricar el textil al modo del Pas-de-Calais en Asia. Todo esto proviene de la gramatización. 
Philipe Petit: Una vez que se ha dicho esto, ¿qué es lo que ocurre en el siglo $\mathrm{XX}$ ? ¿Es el siglo XX todavía un nuevo estadio en la gramatización?

Bernard Stiegler: Este otro estadio de la gramatización comienza, en realidad, en el siglo XIX, desde 1835, con el daguerrotipo y su consecuencia: la fotografía. Luego vino el telégrafo y sus consecuencias, el teléfono y el fonógrafo, las ondas de radio, el cinematógrafo, pero también la mecanografía que puso a punto la compañía americana que luego se volverá la IBM. Todo tipo de aparatos se desarrollan con tecnologías de lo simbólico cuyos efectos van a concretarse sobre todo a comienzos del siglo XX y con la Primera Guerra mundial: la radio y la fotografía harán su revolución. Fue entonces cuando lo sensible de la percepción, bajo todas sus formas, se vuelve reproducible, lo que Walter Benjamin analiza especialmente como reproducción mecanizada de las obras de arte. Es esta tecnología industrial de la producción de símbolos la que, al volverse industria cultural, engendra el segundo estadio de la proletarización.

Philipe Petit: Antes de desarrollar este punto, ¿podrías explicar el primer estadio de la proletarización? ¿Qué es la proletarización?

Bernard Stiegler: Hay un malentendido histórico sobre este punto en el que, por lo demás, el marxismo es muy infiel al pensamiento de Marx. Este malentendido plantea que el proletariado es la clase obrera ${ }^{5}$. Ahora bien, esto es absolutamente falso. Nunca Marx dijo que el proletariado fuera la clase obrera. Marx dijo que la clase obrera era la primera capa destinada a la proletarización. En Marx, el proletariado es el trabajador que pierde su habilidad porque este saber ha pasado a la máquina. El siglo XIX es el siglo de la potenciación de la producción maquínica, del desarrollo del proletariado que reemplaza a los obreros, lo que le va a permitir al capitalismo tener ganancias de productividad colosales, insospechables a comienzos del siglo XVIII, porque el paso de la habilidad a la máquina permite la baja en los costos de producción y la masificación de los mercados. El resultado económico de la gramatización es la realización de enormes economías de escala. Y durante cerca de dos siglos todo esto va a funcionar muy bien...

Philipe Petit: ¿Hasta el hundimiento que usted diagnostica hoy?

Bernard Stiegler: Durante el primer siglo de su realización, el capitalismo industrial no dejó de prosperar, de reestructurarse como se dice hoy ${ }^{6}$. Luego

$5 \quad$ Es también el punto de vista de Jacques Rancière (1981), que habla en realidad de la clase obrera no proletarizada.

6 Incluso sucede si evidentemente esto no dejó de hacerse sin tensiones. Por ejemplo, la siderúrgica francesa, en la lucha internacional que comenzaba en el siglo XIX, no tenía ningún deseo de cambiar lo que fuera porque 
encontró lo que Marx llama la baja tendencial de la tasa de ganancia, de donde resultan los problemas de superproducción. Las ganancias de productividad son tales que las capacidades de producción se vuelven más grandes que las posibilidades de absorción de esta producción, y que las inversiones ya no pueden ser mitigadas.

Philipe Petit: ¿Y es acá cuando se va a desarrollar, en el siglo XX, lo que usted llama la segunda fase de proletarización?

Bernard Stiegler: En efecto. Lo que va a ser proletarizado ya no es, entonces, la habilidad del productor, sino la mundanidad del consumidor. La proletarización es esencialmente una privación de saber que doblega al proletario sobre la necesidad. El proletario está sometido a sus necesidades, y es verdad tanto del productor como del consumidor que está totalmente sometido al reino de las subsistencias por donde pierde su capacidad de existencia. Esto es lo que yo llamo la pérdida de la mundanidad.

Philipe Petit: ¿Por qué hablar de la proletarización de la mundanidad?

Bernard Stiegler: Porque el proletario no es el autor de sus modos de existencia; ya no es quien los inventa en el seno de lo que Simondon (2009) llama un proceso de individuación psíquica y colectiva. Antes bien, ellos le son impuestos por el mercadeo, tanto bajo la forma de nuevos productos como de nuevos servicios, de la misma manera en que los modos de producción le son impuestos al productor proletarizado. El nuevo proletario, condenado a consumir - es decir, sometido a la subsistencia que, por lo demás, se va haciendo cada vez más compleja por la creación continua de necesidades nuevas - se agota al descubrir que entre más consume, más frustrado está y más pierde el sentimiento de existir. Es lo que escribía Richard Durn en su diario íntimo, poco antes de masacrar al

consideraba que estaba protegida por el Estado que había puesto barreras aduaneras al acero inglés, de mejor calidad. La siderúrgica inglesa, que había adoptado los altos hornos Bessemer, desarrollaba técnicas de producción completamente nuevas. Producía un acero menos caro y de mejor calidad. Y, como el Estado francés había puesto barreras para impedir al acero inglés entrar en Francia, los maestros de forjas lorenos continuaban fabricando el acero como antes; no querían sacrificar una parte de sus beneficios invirtiendo en los nuevos modos de producción; no querían formar nuevos obreros más calificados; no querían cavar canales para hacer circular el carbón y el hierro, etc. Querían permanecer en su modo de producción arcaico. Y luego las máquinas de vapor comenzaron a ser más rápidas: los trenes superaron los treinta kilómetros por hora, los rieles en hierro se fueron gastando más rápido hasta el punto de que hubo que cambiarlos cada cinco años. Fue necesario, entonces, reemplazar la infraestructura ferroviaria por rieles de acero. Se compró acero inglés. Fue en ese momento cuando la siderúrgica francesa debió pasar a los métodos ingleses de producción. Cuando un sistema capitalista gana dinero, mientras lo gane no quiere cambiar su modo de producción. Excepto que la potencia pública se lo obligue. 
concejo municipal de Nanterre con pistola-ametralladora (Stiegler, 2003). Y es una consecuencia de lo que Simondon llama la desindividuación.

Philipe Petit: ¿Lo que explica su preocupación por articular Simondon con Foucault?

Bernard Stiegler: Sí. Esta proletarización engendra un proceso de pérdida de individuación generalizada, que es bastante próxima a lo que Foucault (1998) describe como una desubjetivación por el hecho de la individualización (pp. 216, 221-225) ${ }^{7}$. La consecuencia es un hundimiento de la libido. La economía libidinal capitalista ha sido el sistema de transformación social y de adhesión a esta transformación más eficaz que hayamos conocido; se mundializó, trastornó al planeta por completo, alteró radicalmente todos los modos de vida, y ha ejercido un poder de atracción sobre todas las formas existentes de civilización, sean monoteístas o no. Pero hoy está agotado.

Philipe Petit: ¿Y no tendremos que alegrarnos por esto?

Bernard Stiegler: No. Para nada me alegra; me inquieta. Pero pienso también que no es una situación insuperable. Todas las sociedades, todas las civilizaciones alcanzan un día sus límites, y entre más reciente sea una civilización, menos duran, más corta es la duración de su vida.

\section{Referencias}

Auroux, S. (1994). La révolution technologique de la grammatisation. Lieja: Mardaga

Bataille, G. (2007). La parte maldita. Las Cuarenta.

Bernays, E. (2007). Propaganda. Comment manipuler l'opinion en démocratie. La Découverte.

Châtelet, G. (2002). Vivir y pensar como puercos. De la incitación a la envidia y al aburrimiento en las democracias occidentales. Lengua de Trapo.

Donin, N. y Stiegler B. (Eds.). (2004). Cahiers de médiologie 18. Révolutions industrielles de la musique. Éditions Fayard.

Foucault, M. (1968). Las palabras y las cosas. Una arqueología de las ciencias humanas. Siglo Veintiuno Editores.

Foucault, M. (1998). Vigilar y castigar. Nacimiento de la prisión. Siglo Veintiuno Editores.

Himanen, P. (2002). La ética del hacker y el espíritu de la era de la información. Destino.

Kant, E. (1964). Filosofía de la historia. Editorial Nova.

Véase, por ejemplo, Michel Foucault (1998, pp. 216, 221-225) y mi comentario en Prendre soin: de la jeunesse et des générations (Stiegler, 2008a), capítulos 8 y 9. 
Kant, E. (1978). Crítica de la razón pura. Alfaguara.

Leroi-Gourhan (1970). El gesto y la palabra. Universidad Central de Venezuela.

Petit, P. (2008). À propos de l'économie libidinale capitaliste. En B. Stiegler (comp.), L'économie de l'hypermatériel et psychopouvoir. Entretiens avec Philippe Petit et Vincent Bontems (pp. 1-46). Mille et Une Nuits.

Rancière, J. (1981). La Nuit des prolétaires. Fayard.

Simondon, G. (2007). El modo de existencia de los objetos técnicos. Prometeo Libros.

Simondon, G. (2009). La individuación: a la luz de las nocioones de forma y de información. La Cebra/ Cactus.

Stiegler, B. (2002). La técnica y el tiempo 1. El pecado de Epimeteo. Hiru.

Stiegler, B. (2003). Aimer, s'aimer, nous aimer. Du 11 septembre au 21 avril. Galilée.

Stiegler, B. (2004). Mécréance et discrédit. 1. La décadence des démocraties industrielles. Galilée.

Stiegler, B. (2006). La télécratie contre la démocratie. Lettre ouverte aux représentants politiques. Flammarion.

Stiegler, B. (2008a). Prendre soin: de la jeunesse et des générations. Flammarion.

Stiegler B. (2008b). L'économie de l'hypermatériel et psychopouvoir. Entretiens avec Philippe Petit et Vincent Bontems. Mille et Une Nuits. 